\title{
Divadlo é “teatro", e que teatro!
}

\section{Cristina Guerra}

Praga tem uma vida cultural muito intensa: por todo o lado se desenvolvem e anunciam novos acontecimentos artísticos, entre exposições, concertos, festivais, ciclos de cinema e espectáculos de dança. E o teatro não foge à regra: esta cidade é merecidamente considerada um dos maiores centros europeus da arte teatral. 0 amor dos checos pelo teatro (em checo, divadlo) e por tudo o que tenha que ver com esta arte, aliado ao incontestável alto nivel do desempenho dos actores, às interpretações interessantes dos encenadores e à própria natureza das suas experiências teatrais - tudo isto faz com que os teatros checos sejam realmente muitíssimo frequentados, não só pela população local, mas também por todos os que se interessam pela cultura deste país.

Historicamente, o teatro profissional checo apareceu no início do século XIX aliado à vontade de os patriotas criarem uma cultura nacional viva e demonstrarem a unidade da nação. A fundação do Teatro Nacional (Národn Divadlo) em 1868 foi a grande manifestação deste desejo (e para a recolha de meios contribuiu todo o país, desde as mais pobres aldeias à cidade de Praga, juntando os camponeses aos representantes da aristocracia nesse projecto nacional). A constituição do teatro checo representou a separação do alemão, com base na composição de peças em língua checa (como as do dramaturgo de grande mérito J. K Týl, 1808-1856). No mesmo sentido, desenvolveu-se também a ópera (com as obras de B. Smetana, 1824-1884, e A. Dvořák, 1841-1904) e 0 teatro de marionetas.

No início do século XX, começaram a fundar-se, um atrás do outro, os teatros dramáticos checos, como foi por exemplo o caso do grande Divadlo na Vinohradech, em 1907. Considera-se que o período de florescimento da arte teatral checa é o da Primeira República (19181945) e talvez tenha sido então que se formou um certo "culto" muito específico do teatro na sociedade, que sobrevive até hoje. Na altura, ganharam fama internaciona as peças de Karel Čapek - R.U.R(1920) e Doença branca (1937), entre outras -, as experiências vanguardistas de Jiři Voskovec (1905-1981) e Jan Werich (1905-1980), com
Cristina Guerra é licenciada em Artes do Espectáculo e está actualmente a

frequentar a Universidade Carlos a formação do seu Osvobozené Divadlo (1923), e também as de E.F. Burian (1904-1959). Foi nesse periodo que se expandiram em grande número os géneros dramáticos e se desenvolveu o trabalho dos actores na linha de Stanislávski.

Depois de 1948, a reorganização da vida teatral foi assumida como questão de princípio e todos os teatros foram nacionalizados e utilizados como meios de propaganda comunista; a estética pretendida era exclusivamente a do realismo socialista.

No início dos anos 50, na altura da EXPO-58 em Bruxelas, para apresentar da melhor maneira o "rosto nacional da Checoslováquia", foi criado o supermoderno teatro Laterna Magika que, de forma quase milagrosa, antecipou a prática mundial do pós-modernismo com as suas colagens e uma total mistura dos géneros. 0 Laterna Magika, produzindo uma combinação de drama, bailado e cinema, é hoje em dia um dos teatros mais visitados, apesar de se ter tornado um antro do kitsch mais dirigido aos turistas.

Nos anos 60, ganhou fama o "teatro de pequenas formas" (Na Zábradli, Semafor). De entre os dramaturgos, destacou-se uma jovem geração que integrava Pavel Kohout, Václav Havel e Milan Kundera, enquanto na encenação se distinguiam Alfréd Radok e Jan Grossman. Todos estes artistas atraíam a atenção de um público muito vasto devido aos seus trabalhos de carácter informal e não conformista em relação à situação social da sua época, pelo que poderá dizer-se que foi nos espectáculos do teatro Na Zábradlí que "cresceram" aqueles que viriam mais tarde a fazer a Revolução de Veludo de 1989.

No final dos anos 80 , surgiu mais uma tendência do moderno teatro checo, imitando a tradição do décadence do século XIX, que os surrealistas checos promoveram em meados do século XX. 0 "teatro negro" continua ainda hoje a trabalhar neste estilo, na fronteira entre realidade e fantasia.

Actualmente existem mais de 50 teatros dramáticos em Praga. Os repertórios são muito variados, integrando peças contemporâneas de autores checos e europeus, mas também os clássicos, abordados ora de forma tradicional (o caso do teatro Na Vinohradech) ora através de novas perspectivas interpretativas e cénicas (como faz o teatro Dejvické). 0 Teatro Nacional e a Ópera Estatal (Státni Opera Praha), com o seu carácter de "teatros-museus", recorrem repetidamente ao cânone da dramaturgia checa (no primeiro caso, há mais de cem anos que são apresentadas A noiva vendida, de B. Smetana (1866) e A sereia, de A. Dvořák (1900)), ou fazem encenações dos grandes clássicos europeus (por vezes, aliás, nem tanto clássicos, nem tanto europeus) no caso da Ópera Estatal. Contudo, nota-se uma certa preferência pelo romantismo europeu por parte da Ópera Estatal.

De entre os teatros dramáticos de maior interesse contam-se o Divadlo pod Palmovkou, o Strašnické Divadlo, o Dejvické Divadlo, Na Zábradli e o Teatro em Žižkov de Jára 


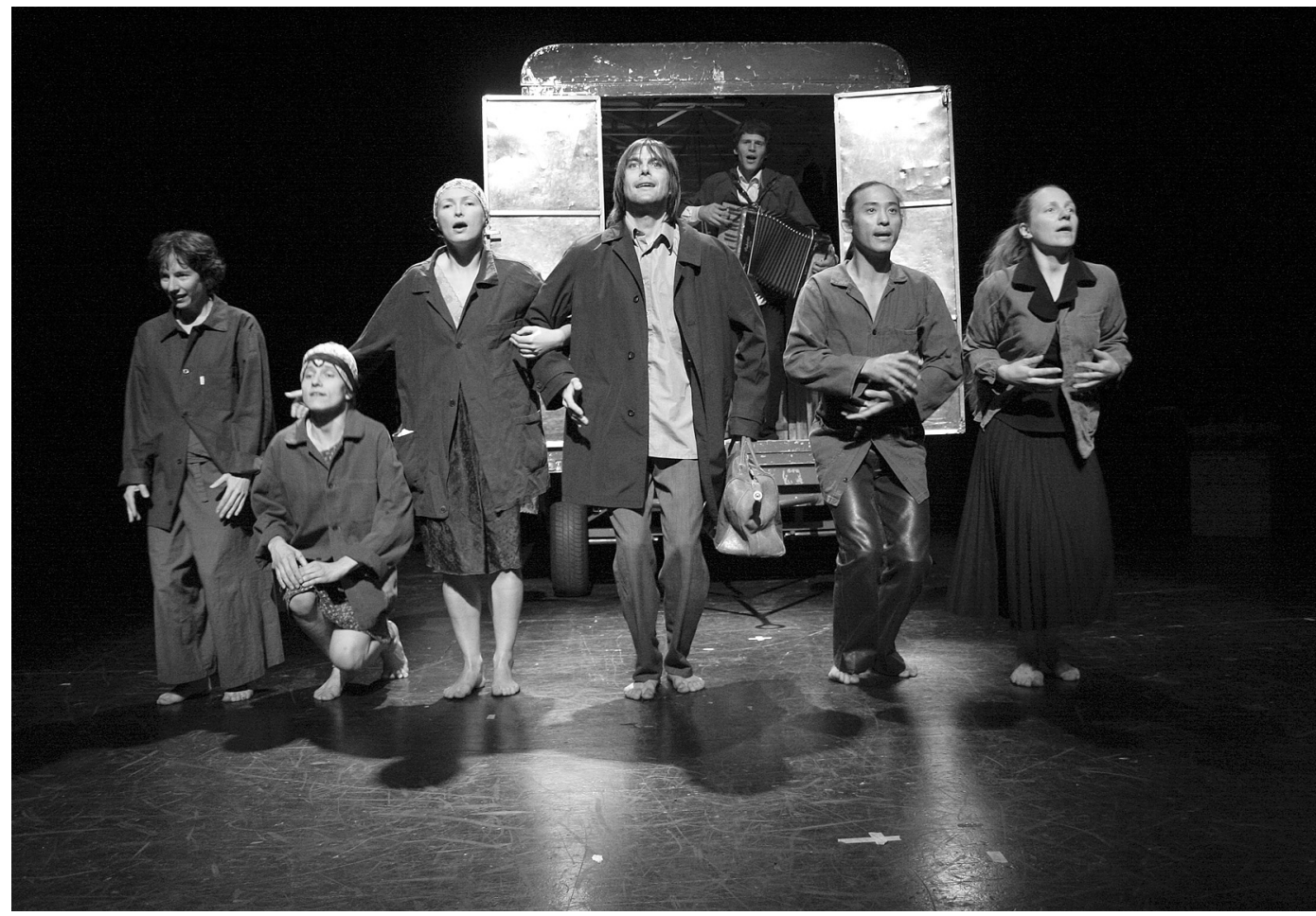

Sclavi - Canção de um

emigrante,

enc. Viliam Docolomansky,

Farm in the Cave 2008

(Cécile da Costa,

Maja Jawor,

Hana Varadzinová

Róbert Nižnik,

Roman Horák,

Jun Wan Kim

e Eliška Vavríková),

fot. Michal Selinger.
Cimrman (Žižkovské Divadlo Járy Cimrmana). Este último caso é um fenómeno impressionante da cultura checa: Jára Cimrman é uma figura fictícia, criada pelos actores famosos L. Smoljak e Zdeněk Svěrák, é um herói checo nacional dotado de todos os talentos, entre eles o da escrita (pertencem-Ihe 14 peças), mas, antes de mais, provido de sentido de humor e de um conhecimento profundo da especificidade do carácter checo. As suas peças têm sido êxitos de bilheteira tão grandes que são necessários meses para se conseguir entrada.

Em relação aos teatros onde se pode ir mesmo sem se perceber a língua checa, existem os do "teatro negro" e vários teatros de marionetas que prescindem da palavra. No entanto, alguns outros teatros, talvez menos conhecidos mas que merecem uma especial atenção, são grupos de carácter alternativo. Um deles chama-se Farm in the Cave (Farma v Jeskiny) e é um teatro-estúdio criado em 2001, dirigido pelo encenador eslovaco Viliam Docolomanský. Trata-se de um grupo que baseia os seus espectáculos em tudo o que é possivel fazer e mostrar em palco: seja com pantomima, dança, texto ou música. É um teatro que se pode considerar não tradicional e isso prende-se também com o efeito que os seus trabalhos criam no público mais do que uma reacção racionalizada, as coisas que fazem em palco provocam verdadeiro impacto sensorial nos espectadores. 0 director artístico, que em 2007 concluiu a sua tese de doutoramento Expressão como uma transmissão de experiência humana, desenvolve nesta companhia os seus métodos de exploração do corpo e da voz, que pretendem que, entre espectador e actor, se dê um contacto que vai para além do que pode ser expresso pela linguagem falada. Partindo ou não de uma base textual, os espectáculos de Farm in the Cave resultam também de um trabalho de pesquisa muito especial: os elementos da companhia fazem expedições com o fim de estabelecerem contacto com culturas minoritárias e aí recolherem materiais para os seus espectáculos (música, dança e histórias de vida). A primeira experiência deste género foi uma expedição à Andaluzia em 2001, onde 0 grupo estabeleceu contacto directo com a comunidade cigana, os toureiros, o flamenco, e estudou a vida de Federico Garcia Lorca (grande inspiração para Docolomanský). Baseado na vida e nos poemas do poeta, o espectáculo Sonetos de amor sombrio (Sonnets of Dark Love) foi o momento da fundação da companhia.

Um dos trabalhos mais recentes deste grupo é o espectáculo Sclavi - Canção de um emigrante, estreado em 2005. Baseado na novela de Karel Čapek, Hordubal, integra uma intensa pesquisa que o grupo levou a cabo nas aldeias rutenianas do leste da Eslováquia, entre 2003 e 2007, durante a qual os membros de Farm in the Cave recolheram cartas de emigrantes, canções étnicas e tradicionais, bem como rituais e depoimentos dos emigrados. Em Março de 2005 estrearam.

Sclavié a história do sofrimento de um agricultor emigrante que regressa da América, chega à sua aldeia na Eslováquia e depara-se com um enorme vazio: a sua terra natal já não é a sua, os "seus" já não são os seus, todos o evitam e rejeitam. 0 "sonho americano" que resultou em desilusão, a não integração no pais de "acolhimento" e, ao mesmo tempo, a perda das raizes o tema não é novo mas não deixa por isso de ser importante. Sclavi, em latim, significa eslavos, mas também escravos, e isso lembra-nos também o típico fenómeno dos emigrantes eslavos como vítimas de exploração e exclusão social. A situação é aparentemente específica, mas o espectáculo é dirigido a toda a gente: a linguagem é antes de mais a da expressão corporal, com dança e música. Há também texto falado, mas, como se explica no programa, a língua usada é ucraniana, ruteniana, eslovaca, checa e inglesa, e ainda o dialecto da Eslováquia de Leste, pelo que nem sequer os checos percebem tudo, facto de menor importância, uma vez que a linguagem se torna entendivel, ajudada que é pela sua redução ao som 


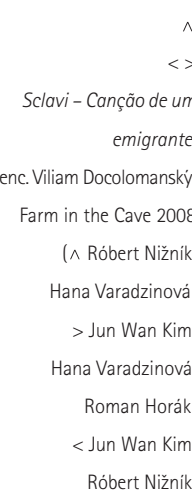

Hana Varadzinová)

fot. Michal Selinger.

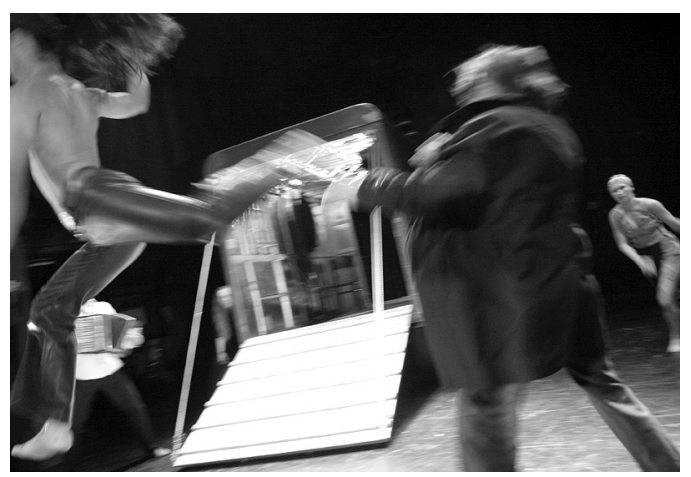

significante e por operações de teatralização (entendemos o que se passa pelo contexto, pela mímica ou pelas entoações) e de combinação com a música e as danças dos actores. 0 que importa, afinal, é que chegamos a experimentar de facto as mesmas emoções e as mesmas amarguras que estas personagens. 0 que é magnífico neste espectáculo é que, através dos meios que usa e da sua linguagem simbólica, a nostalgia, o lamento e o desespero tornam-se claros para nós e atingem-nos como um "murro no estômago", abanam-nos, lembrando-nos a nossa comum condição humana. 0 espectáculo foi representado em vários países com grande êxito, portanto, é verdade que não é preciso ser eslavo nem escravo, nem emigrante pobre da aldeia, que perdeu tudo, para o entender.

Tudo começa com a porta de um carroção vermelho a abrir-se com estrondo e de onde sai um grupo de actores (de várias nacionalidades eslavas, entre checos, polacos, sérvios, ucranianos); parece uma espécie de coro que faz um preâmbulo dançado e cantado, no qual se reconhecem algumas palavras sobre a América; o tom é de euforia e esperança.

Este coro desenrola o fio narrativo: a chegada do emigrante à sua pátria, à aldeia, e depois a sua tentativa de reintegração e consequente rejeição pelos outros. A linguagem utilizada é corporal e metafórica: as raparigas fogem dele, espreitam pelas janelas do carroção e dizem "está fechado, venha mais tarde" em inglês; a sua mulher quando ele tenta tocar-Ihe, evita o seu contacto e perguntaIhe "chá? café? água?"; os homens conspiram contra ele.

Todo o espectáculo se desenvolve como uma espécie de cacofonia: várias acções a acontecerem ao mesmo tempo, música vinda de vários lados, personagens a entrarem e a falarem, ou a cantarem e a representarem com pantomima. Tudo se assemelha a uma gigantesca canção cuja duração é de uma hora. Nesta grande "orquestra", a energia corporal é incrivel, crua, animalesca. As frases das cartas dos emigrantes são ditas em
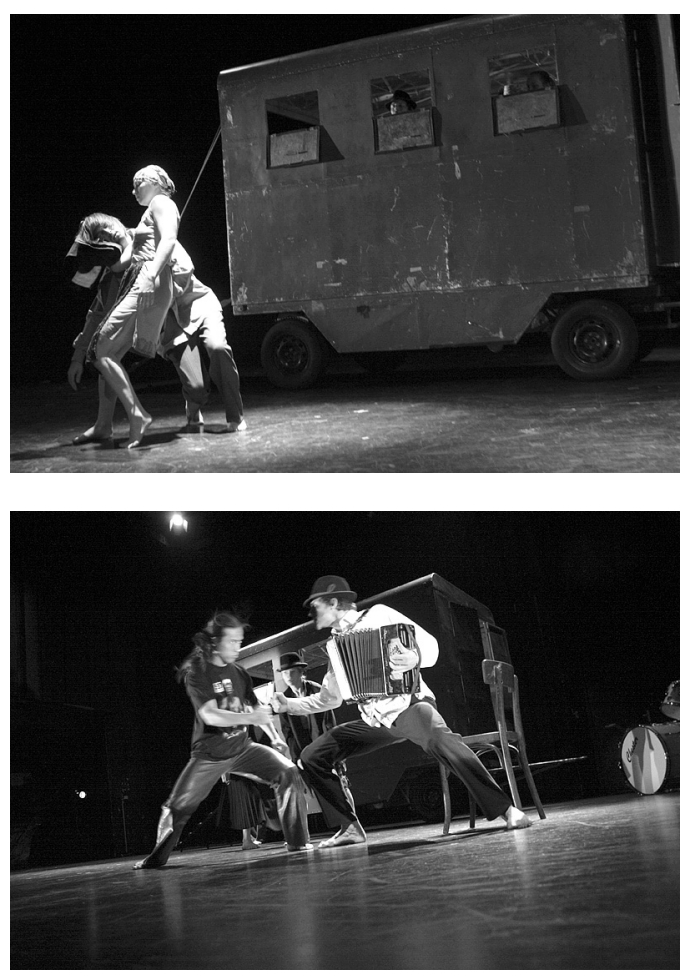

consonância com a música ou intercaladas com ela. Produzse a sensação de um grande colectivo, uma multidão de seres humanos sem relações definidas, um baile de figuras que se agitam desamparadas, perdidas.

Para exprimir a ideia da perda de identidade, há uma metáfora muito bela e poética: logo no inicio, a imagem do emigrante com uma mala vazia, onde ele mete os seus pés. Não trouxe nada, nenhuns bens materiais, só tem a si próprio, ou faz de si o seu próprio fardo. Se quisermos interpretar esta metáfora da mais elementar maneira, nos termos da sociologia vulgar, ela pode ser vista como uma imagem do fracasso económico em situação de emigração. Mas, de facto, o que mais se acentua é o vazio da perda: se não há ligações, relações, pertences, talvez não haja também "pessoa"... É também com esta imagem que o espectáculo termina, fechando o círculo. Noutro momento a personagem tira do bolso um fio eléctrico, tenta prendêlo algures no ar, tenta, com esforço desesperado, encaixálo nalgum lado. Para ligar a luz, vencer a escuridão? Para instalar uma fonte de energia no espaço vazio? No mesmo momento, uma outra personagem masculina faz, em inglês, um discurso irónico sobre o sonho-cliché americano.

0 cenário é constituído pelo tal carroção de gado que se integra na coreografia do espectáculo, funcionando como a casa móvel destas personagens, mas também como o objecto dentro do qual e em torno do qual tudo acontece: as portas abrem-se e fecham-se com estrondo, os actores saem de lá, espreitam pelas janelas, penduram-se do tejadilho, sentam-se no tejadilho... À nossa direita há uma bateria manuseada por um dos elementos. Cria-se um espaço imaginário que, ao mesmo tempo, existe e não existe: é o espaço em que vivem as personagens, mas todo o acompanhamento musical é criado em palco pela bateria, um acordeão e por objectos que não sendo instrumentos musicais prestam-se a sonoridades variadas como, por exemplo, quando os actores fazem barulho a bater com colheres no carroção movido pelos próprios actores. Assim 


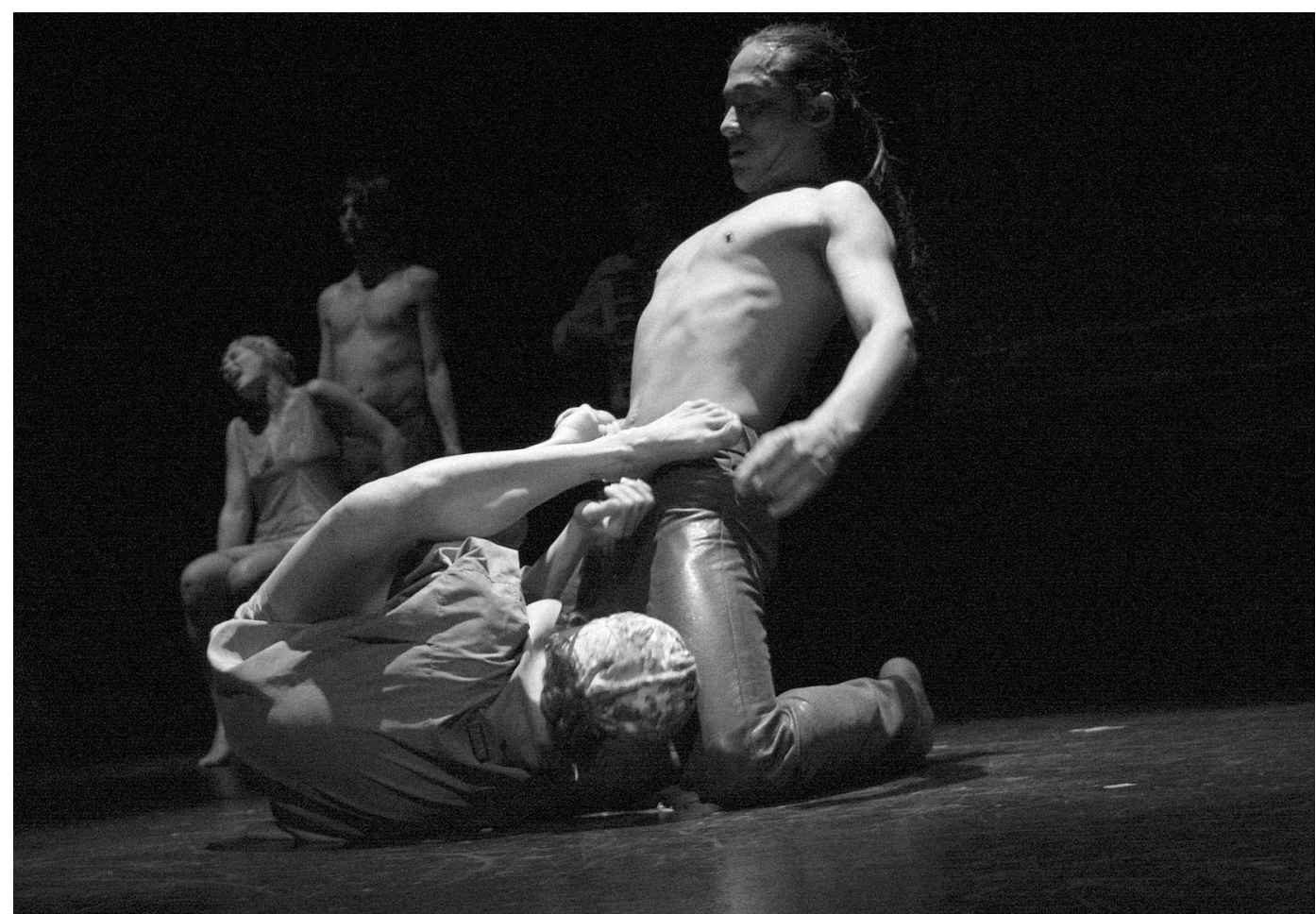

Sclavi-Canção de um emigrante, enc. Viliam Docolomanský Farm in the Cave, 2008 (Hana Varadzinová, Róbert Nižník, Maja Jawor, e Jun Wan Kim) fot. Michal Selinger. se elimina a fronteira entre a teatralidade e a vida, entre 0 actor e a sua personagem.

Os figurinos são roupas simples de agricultores e, por várias vezes, todas as personagens aparecem vestidas exactamente da mesma maneira, criando-se um ambiente em que o individual não interessa e se torna muito mais importante o destino colectivo. As figuras individuais nivelam-se, confundem-se, misturam-se: numa das danças, as mulheres levantam as camisolas e tapam as caras com elas; a personagem principal despe a sua camisa e veste com ela uma das raparigas; roubam a roupa uns aos outros; acompanham o andar dos outros ou tentam acertar o passo.

Talvez devido ao seu carácter de algum modo ritualizado, a dança tem neste espectáculo qualquer coisa de muito primitivo, instintivo, como se nada ali fosse intelectualizado, mas apresentando as pessoas no seu estado animal. Dai decorrem também os repetidos elementos de energia sexual, da nudez, comida e bebida. 0 próprio facto de rejeitarem o familiar recém-chegado lembra a rejeição do mais fraco por uma matilha, enquanto as lutas dançadas entre os homens lembram os machos que disputam o primeiro lugar a outros machos, a luta pela supremacia do mais forte.

E o final: o protagonista, prostrado como morto, novamente com os pés dentro da sua mala. Foram os outros que o levaram à exaustão? Ou tudo o que a vida Ihe trouxe ou lhe negou? Mas antes do ponto final, uma inesperada nota de humanismo: as mesmas pessoas, que antes o desprezavam, tentam reanimá-lo.

Não é fácil explicar este espectáculo em termos exactos de lógica, uma vez que usa uma linguagem teatral que visa o encantamento, talvez na mesma linha em que Antonin Artaud tentou criar o seu teatro. É muito agressivo e quase alucinatório, provocando um abalo no espectador. Houve quem achasse que o espectáculo era "sensacionalista", mas a poesia de que está impregnado compensa uma certa sensação de exagero. Em qualquer caso, ficamos com a sensação de que acabaram de dizernos uma verdade que nunca vamos esquecer.

Um espectáculo como este não pode deixar de nos fazer pensar por que razão num país que já faz parte, orgulhosamente, da União Europeia e tem os cidadãos numa situação diferente da dos não-membros (ucranianos, p. ex.) na imigração, as pessoas continuam a preocuparse com este problema? Por que se solidarizam ou se identificam com os imigrados "inferiores"? Será que falhou não só o "sonho americano", mas também o "mito europeu"? Não há dúvida de que este tipo de teatro é interventivo e se baseia numa realidade social.

E se o espectáculo Sclavi nos faz pensar nestes problemas, de uma forma ainda mais directa o faz outro grupo de teatro contemporâneo, NoD, com o seu espectáculo Europeus(Evropané). Encenado por Jiři Adámek, este espectáculo apresenta o conceito de europeu, primeiro como non-sense, depois como uma utopia: um grupo de duas actrizes e dois actores, vestidos uniformemente de branco e com máscaras, apresentam-se como seres não humanos manipulados, quase bonecos; movimentandose numa roda-viva pelo palco, a sua linguagem baseia-se em sons, onomatopeias, palavras soltas compreensiveis ou não, ou então através do recurso a línguas diferentes, criando um mundo no qual ninguém se entende e a comunicação é impossivel. E quando de repente um dos actores faz um discurso em língua fluente - recita os princípios da Constituição da União Europeia - percebemos que nem estas palavras são de fácil compreensão: o discurso é difícil, soa a falso, parece que as palavras não fazem sentido. 0 espectáculo termina com a utopia: aparece a imagem idilica de um arco-iris a envolver o cenário e, ao mesmo tempo, cai neve. Cria-se uma forte sensação de desconforto - talvez porque a realidade nua e crua veio derrubar mitos e ilusões e criar um novo desenraizamento. Assim vai o teatro em Praga. 